\title{
Evaluation of usage patterns and user perception of the drug-drug interaction database SFINX
}

Marine L. Andersson, Ylva Böttiger, Pia Bastholm-Rahmner, Marie-Louise Ovesjo, Aniko

Veg and Birgit Eiermann

\section{Linköping University Post Print}

\section{Tweet}

N.B.: When citing this work, cite the original article.

Original Publication:

Marine L. Andersson, Ylva Böttiger, Pia Bastholm-Rahmner, Marie-Louise Ovesjo, Aniko Veg and Birgit Eiermann, Evaluation of usage patterns and user perception of the drug-drug interaction database SFINX, 2015, International Journal of Medical Informatics, (84), 5, 327333.

http://dx.doi.org/10.1016/j.ijmedinf.2015.01.013

Copyright: Elsevier http://www.elsevier.com/

Postprint available at: Linköping University Electronic Press http://urn.kb.se/resolve?urn=urn:nbn:se:liu:diva-117198 


\section{Evaluation of usage patterns and user perception of the drug-drug}

interaction database SFINX

Marine Andersson ${ }^{1}$, Ylva Böttiger ${ }^{1}$, Pia Bastholm-Rahmner ${ }^{2}$, Marie-Louise Ovesjö ${ }^{1}$, Aniko Vég ${ }^{3}$, Birgit Eiermann $^{1}$

Affiliations:

1. Division of Clinical Pharmacology, Department of Laboratory Medicine, Karolinska Institutet, Karolinska University Hospital

2. Department of Learning, Informatics, Management and Ethics, Medical Management Centre (MMC), Karolinska Institutet, Stockholm, Sweden

3. Health Services Research at Department of Public Health and Caring Sciences, Uppsala University, Uppsala, Sweden

\section{Correspondence:}

Marine L. Andersson MSc,

Division of Clinical Pharmacology C1-68,

Karolinska University Hospital, Huddinge,

Karolinska Institutet, 14186 Stockholm, Sweden.

Tel.: + 46858581064

Fax: +46858581070

E-mail: marine.andersson@karolinska.se

Keywords: Drug interactions, Decision Support Systems, Clinical, Questionnaires, Medical Order Entry Systems 


\section{Abstract}

Purpose

The aim of the present study was to investigate how prescribers and pharmacists use and perceive the drug-drug interaction database SFINX in their clinical work.

\section{Methods}

A questionnaire was developed with questions aimed at the usage of SFINX, and the perceptions of the database. The questionnaire was sent out to all registered users of the web application of SFINX. The anonymous answers from the target users, prescribers and pharmacists were summarized using descriptive statistics. Statistical analysis was performed on age and gender differences for some questions regarding different usage patterns.

\section{Results}

The questionnaire was sent to 11763 registered SFINX users. The response rate was $23 \%$, including 1871 answers from prescribers or pharmacists. SFINX was reported to be used at least weekly or more often by $45 \%$ of the prescribers and $51 \%$ of the pharmacists. Many prescribers reported using the database during the patient consultation (60\%) or directly before or after (56\%). Among the prescribers, $74 \%$ reported that the information received made them change their action at least sometimes. About $20 \%$ of the prescribers and $25 \%$ of the pharmacists considered the information as irrelevant sometimes or more often.

\section{Conclusion}

Most prescribers and pharmacists reported using SFINX in direct association with a patient consultation. Information received by using SFINX makes prescribers and pharmacists change their handling of patients. DDI databases with relevant information about patient handling might improve drug treatment outcome. 


\section{Introduction}

Drug-drug interactions (DDIs) can cause drug-related problems, both adverse drug reactions and loss of therapeutic effect [1]. DDIs are often avoidable, if the prescriber is aware of the interaction and knows which other therapeutic options are available. A clinical decision support system (CDSS) can provide information about drug-drug interactions or other drug related problems, give advice on how to handle them, and thereby improve quality of prescribing, reducing drug related problems and enhancing patient safety [2-3]. A CDSS containing information with high specificity about drug interactions has also been deemed clinically useful in DDI detection [4-5]. Additionally, alerts should be tiered by severity to increase user compliance and avoid alert fatigue of the users [6]. To maximize the usefulness of a DDI alert system, it should not only point out potentially harmful combinations of drugs, but also provide information on alternative strategies to meet the therapeutic needs of the patient [7-8].

There are several CDSSs addressing DDIs. Substantial variance regarding the content of different DDI databases due to different inclusion criteria, severity grading and other factors have been shown [910]. Several studies point out the need for standardization of assessing DDIs, grading their severity, and writing and structuring the information in the DDI database [11-12].

The SFINX database, developed and used in Sweden and Finland, is available in Sweden through a web application and is also integrated into electronic health record systems (EHR) [8]. Integration into EHR systems varies both for the graphical user interface and how the integration fits into the workflow of the prescribers. The providers of SFINX have no influence on its implementation. To avoid any aspects of integration problems in the investigation and to focus on the assessment of the 
content of SFINX it was decided to limit the study to the web users. SFINX includes approximately 16000 , mainly pharmacokinetic, interactions and is updated four times a year. The web application is available free of charge in Sweden through the Janusinfo website (www.janusinfo.se), which is promoted to all health care professionals [13]. Anyone with an e-mail account can register as a user, including patients or their relatives.

The aim of the study was to explore how prescribers and pharmacists use the SFINX web application in their clinical work, as well as their perceptions regarding the usefulness of the database.

\section{Method}

\section{Setting of the SFINX web site}

The study investigates the user perception of the web application of SFINX. In the web application, contrary to when SFINX is integrated in the EHR, the user has to manually enter all drugs by either their trade name or active substances. SFINX delivers colour coded alerts when a drug list containing drugs with potentially harmful DDIs is entered [8]. The code is related to the SFINX-classification of interactions [8;14], which rates the clinical relevance of a possible interaction from A to D. Red colour stands for DDIs which are clinically relevant and should be avoided (D); yellow for clinically relevant interactions which could be handled by e.g. dose adjustment $(C)$ and white for interactions where the clinical relevance is uncertain or might vary (B) or a minor interaction with no clinical relevance (A).

By clicking the alert button in the web application a short description of the medical consequences of the DDI is retrieved as well as recommendations on how to handle, monitor for, or avoid the specific DDI. Information regarding mechanisms, a summary of the evidence and references are readily 
available through a 'Read more' link. At the time of the survey, there were 9727 interaction pairs included in the database.

\section{Questionnaire}

The questionnaire was created by a panel of physicians, pharmacists and behavioural scientists. The purpose was to receive answers about the demographics of the users, about when and how SFINX is used, which benefits and pitfalls users experience, how often the information influences their behaviour (e.g. prescribing decisions, or how to handle the customer in the pharmacy) and what action that is usually taken. Three different variants of the questionnaire were developed for health professionals, pharmacists and other users, respectively.

The first three questions regarded demographics (age and sex as well as category of user) and led depending on the user category either to ten additional questions for pharmacists or prescribing professionals (primary care and special care physicians, dentists, midwifes and prescribing nurses) or to eight additional questions for other health care personnel, students and patients and their relatives. The scope of the study was to identify the perceptions and perceived needs of prescribers and pharmacists, thus only these answers were included.

The initial demographic questions were followed by questions regarding the frequency and situation in which the database is used. Thereafter, there were questions regarding how often the read more button (to show the mechanism and background text and references) is used, how often the 
information about a DDI causes changes in handling of the patients, the benefits of the database and relevance of the advices.

Some questions had graded answers, some were multiple-choice questions, and the last question had a free text answer for comments and complaints. The electronic survey was presented as a series of web pages with one to four questions per web page.It took approximately 10 minutes to answer the survey.

The whole questionnaire is available as supplementary material.

No validation of the questionnaire was deemed necessary as it was constructed in collaboration by physicians, pharmacists and social scientists and tested by a group of physicians and pharmacists. Easyresearch (http://www. easyresearch.se) [15] was used to make the questionnaire available on the internet.

\section{Study subjects and data collection}

All persons registered as users of SFINX at http://www.janusinfo.se were invited to participate in the study. An e-mail was sent out on November 12, 2009 using the e-mail address provided at the day of registration. The survey was accompanied by a cover letter explaining the purpose of the survey. All e-mails that bounced were subtracted from the analysis. Two reminders were sent by e-mail to nonresponders after the first send out with 2 weeks in between. One week after the second reminder we decided to close the data collection process as, according to the literature, the majority of respondents reply within 36 hours [16]. Data were collected anonymously. Data collection ended at the 17 of December 2009. 
All answers were automatically stored in the system easyresearch[15].

\section{Data analysis}

Descriptive statistics including frequencies were used to describe user demographics and to analyse data on single or multiple questions.

Differences dependent on age or gender were analysed for some of the questions. The effect of age on how often the information from SFINX makes the prescriber change their drug prescription was analysed using Spearman rank correlation. Both age and the answer on the question were divided into 5 ranked levels. Gender difference was analysed pairwise by using Wilcoxon signed rank test

Other differences depending on age were analysed for the questions about how often the prescribers report that they learn from the information, how often they get advice and how often they ignore the information. All analysis were made using Wilcoxon signed rank test.

All statistical analyses were done using R version 2.15.1 [17].

\section{Results}

The questionnaire was sent to the email addresses of 11763 registered SFINX users. The answer frequency was $23 \%$ ( $n=2699$ ). There were 1958 respondents who replied after the first and second emails, and after the last reminder 749 respondents answered the survey. Answers from other than 
professionals were excluded from the analysis ( $n=846$ ). Among the 1871 answers, $75 \%$ were from drug prescribing professionals $(n=1402)$ or pharmacists $(n=469)$. Respondent characteristics are presented in table I. The answers of 828 other users were eliminated from the analysis.

\begin{tabular}{|l|l|l|l|l|l|}
\hline & $\begin{array}{l}\text { Physician, } \\
\text { primary } \\
\text { health care } \\
(\mathbf{n = 3 8 9 )}\end{array}$ & $\begin{array}{l}\text { Physician, } \\
\text { hospital care } \\
(\mathbf{n = 7 3 1 )}\end{array}$ & $\begin{array}{l}\text { Prescribing } \\
\text { nurse/midwife } \\
(\mathbf{n = 2 4 2})\end{array}$ & $\begin{array}{l}\text { Dentist } \\
(\mathbf{n = 4 0 )}\end{array}$ & $\begin{array}{l}\text { Pharmacist } \\
(\mathbf{n = 4 6 9 )}\end{array}$ \\
\hline $\begin{array}{l}\text { M/F /no } \\
\text { answer \% }\end{array}$ & $53 / 46 / 1$ & $48 / 51 / 0$ & $7 / 91 / 2$ & $53 / 48$ & $15 / 84 / 1$ \\
\hline Age <29\% & 9 & 15 & 4 & 3 & 22 \\
\hline Age 30-39\% & 31 & 31 & 14 & 23 & 30 \\
\hline Age 40-49\% & 21 & 21 & 30 & 28 & 24 \\
\hline Age 50-59\% & 22 & 20 & 38 & 30 & 17 \\
\hline Age 60 > \% & 16 & 13 & 13 & 18 & 8 \\
\hline $\begin{array}{l}\text { Age no } \\
\text { answer \% }\end{array}$ & 0 & 0 & 1 & 0 & 0 \\
\hline
\end{tabular}

Table I. Respondent characteristics.

Approximately half of the prescribers (45\%) and pharmacists (51\%) reported using the database every week or more often. Many of the prescribers reported using the database at the time of patient consultation (60\%) or directly before and after patient consultation (56\%). Other uses were for drug utilization reviews or for educational purpose (figure 1). Pharmacists reported using the database mostly when dispensing drugs to patients. 


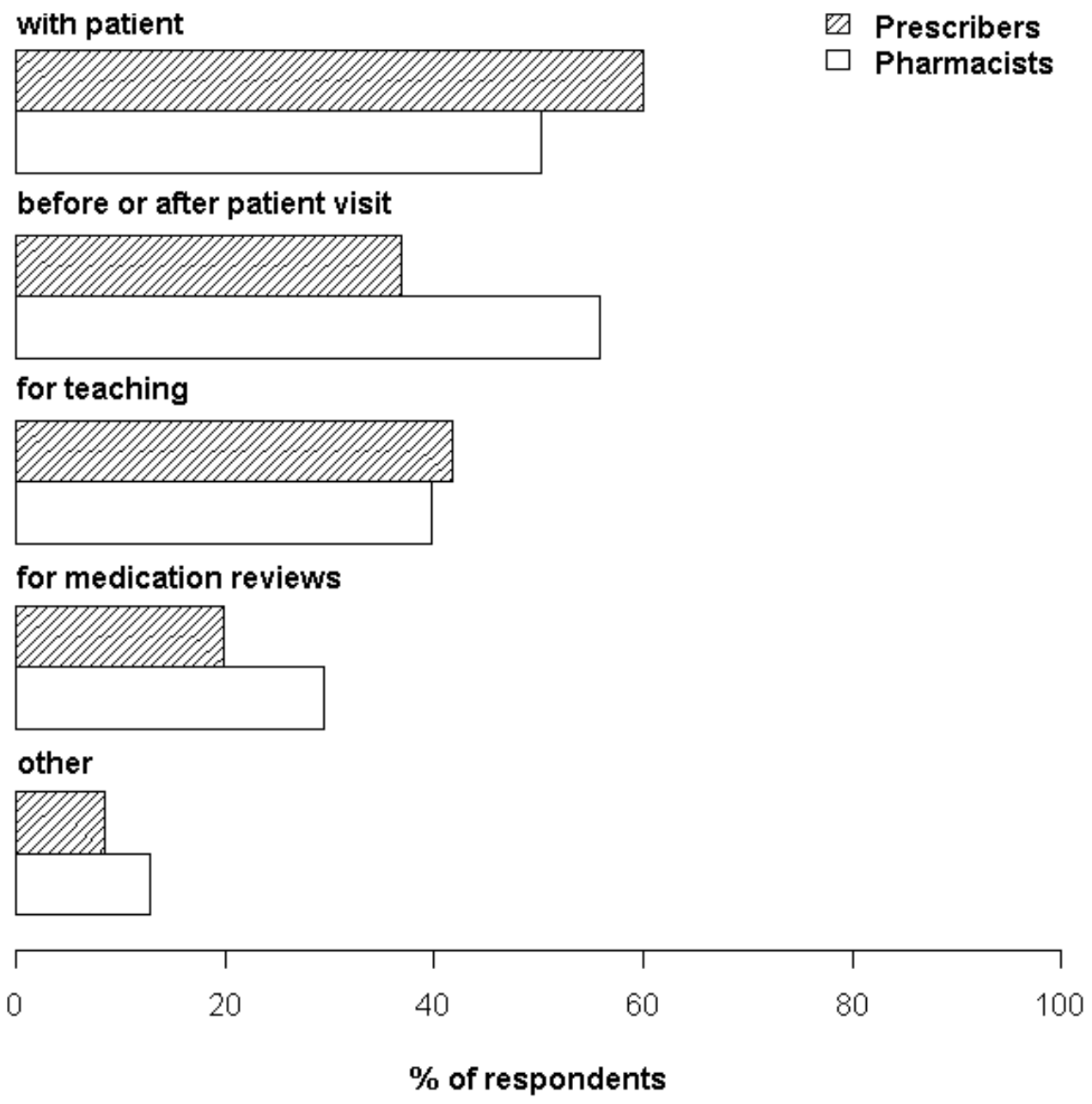

Figure 1. In which situation do prescribers/pharmacists use the database?

In total, $74 \%$ of the prescribers stated that the information provided by SFINX make them change their prescribing or ongoing treatment 'sometimes' or more often (figure 2). The most common action was to change the choice of drug (73\%) followed by informing the patient (47\%) and changing the dose (36\%) (figure 3). Almost all pharmacists reported that the information makes them change their actions (93\%). The most common actions by pharmacists were to contact the prescriber (64\%), or to inform the patient (52\%) (figure 3). 

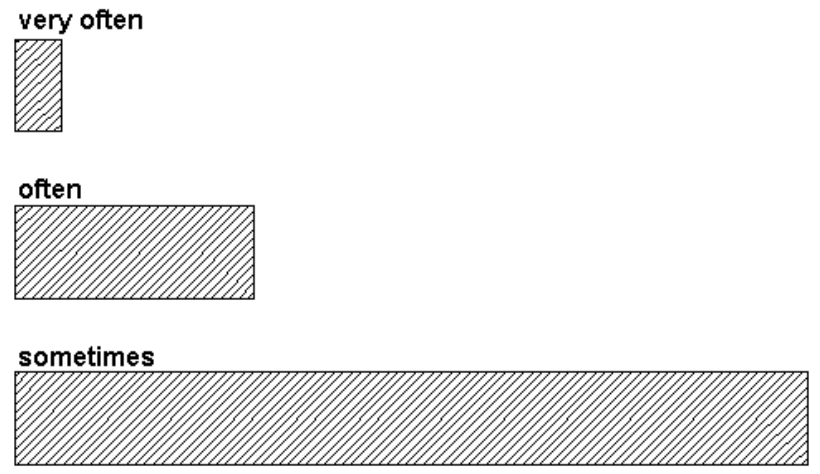

seldom
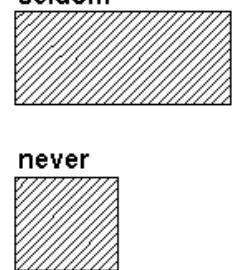

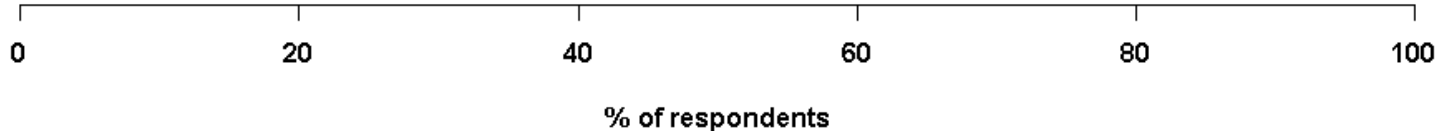

Figure 2. How often does the information in the database make the prescribers change their action?

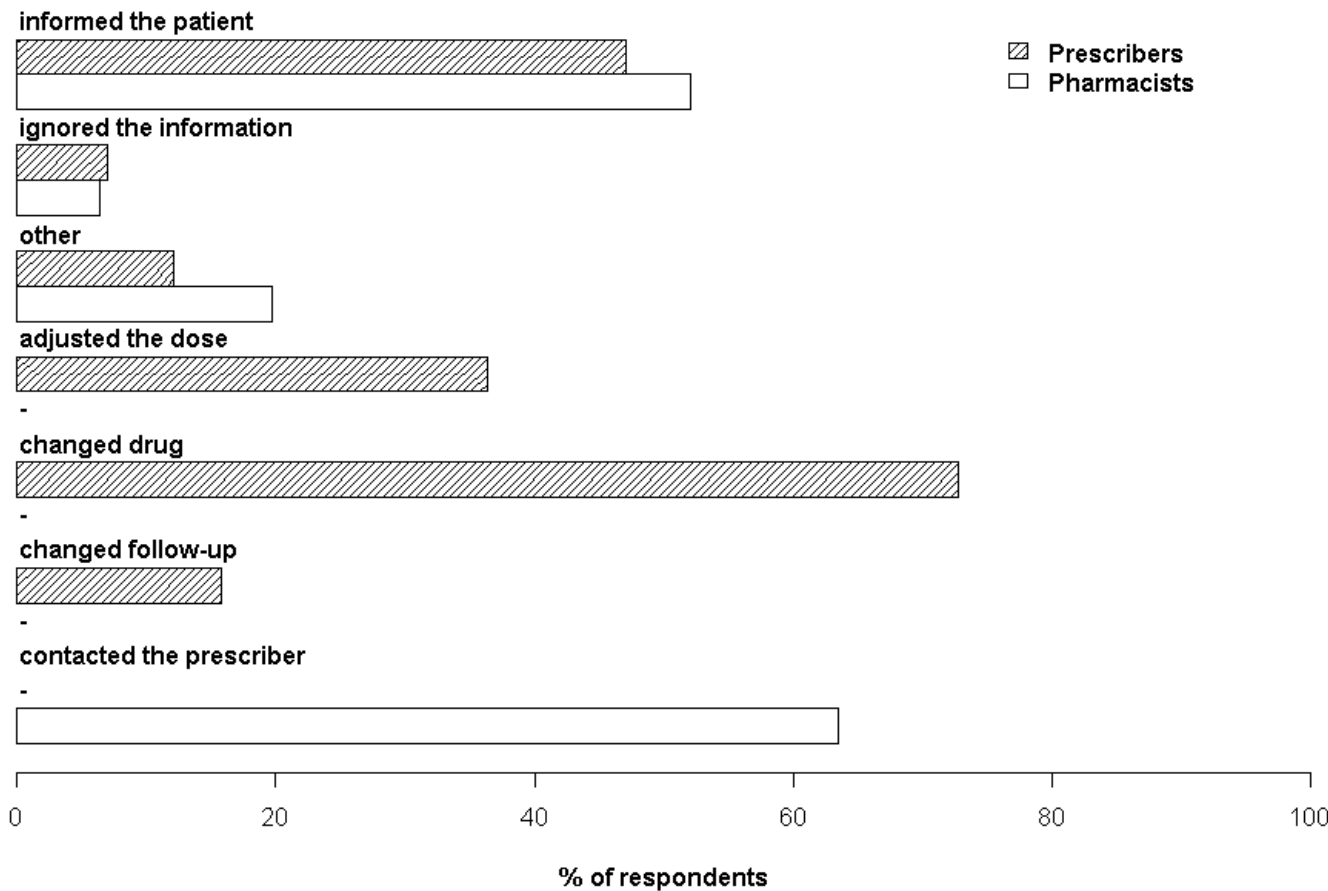


Figure 3 How do the prescribers and pharmacists usually react when reading information from the database? Some questions were presented only to one of the categories. A - sign indicates that this question was not answered by that category of users.

According to prescribers, to learn about interactions (77\%) and to receive assurance about the absence of a drug interaction (72\%) were the two major benefits of using the database. Among pharmacists, the most common help from SFINX was advice on how to handle interactions (76\%), followed by learning about interactions (69\%) (figure 4).

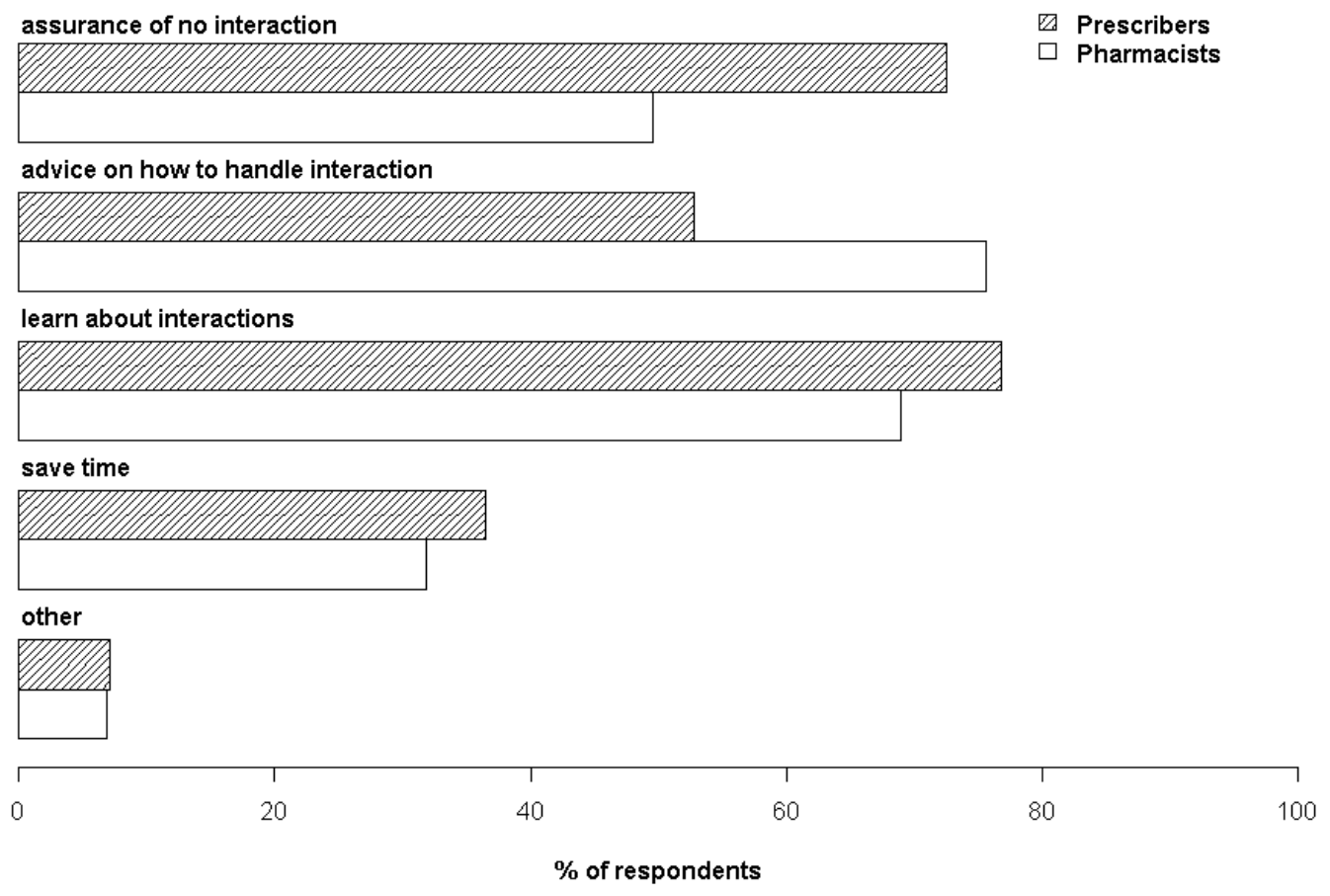

Figure 4. What purpose does the database have for prescribers/pharmacists?

The information in the database was reported to be irrelevant sometimes or more often by $20 \%$ of the prescribers and $25 \%$ of the pharmacists. Almost all of the users (98\%) reported that they would recommend the database to their colleagues. 
When given a warning, $72 \%$ of the prescribers reported that they read the recommendation text. Among pharmacists the corresponding number was $80 \%$. Many of the respondents, especially pharmacists (87\%), reported using the 'read more' function while the corresponding number for the prescribers was $64 \%$.

There was no statistically significant effect of age on how often the respondents change their prescription based on information in SFINX ( $p=0.82)$. However, there was a significant difference between men and women, where women were more likely to change their prescriptions $(p=0.03)$. There were no other significant differences between age groups or genders on the parameters analyzed.

\section{Discussion}

Overall, the users of SFINX seemed satisfied with the application, with $98 \%$ of the respondents recommending it to other colleagues. We found that the database often is used when the prescriber/pharmacist sees the patient or before/after patient visit, indicating that it is useful in the daily work of these professions. The high usage directly when meeting patients could be an indication that the application is user friendly, and that the information given is worth the time and effort spent on entering all the drugs the patient is using. In contrary, Hayward et al. [18] showed that decisions about drug prescribing in primary care were already made a long time before the physician turned to the computer and that integration of decision support systems has to be improved to better fit into prescribers' workflow. This might not apply to the respondents in this study, who actively chose to enter a web site for DDI information, compared with practitioners with integrated CDSS in their EHR systems. 
One strength of this study is the high number of respondents, with more than 1000 prescribers and nearly 500 pharmacists. The response rate $(23 \%)$ is similar to or somewhat higher than for other web-based questionnaires [19-20]. In an Australian study $19.5 \%$ of pharmacists and physicians (out of 2000) responded to a postal survey regarding interaction software [20].

Prescribers' decision to follow advice from DDI systems is very much depending on the quality of the data presented by the system. Severity graded systems to avoid desensitization and improved graphical user interface, as suggested by Ahearn et al. [21], as well as the content of the database and its perceived usefulness, as described by Kortteisto et al. [22], are two important issues for DDI database users to avoid alert fatigue. SFINX contains both a severity grading systems as well as it provides practical advice on patient management, which might reflect the high frequency of users who report the information in the database as relevant.

One of the main benefits of SFINX, reported by both prescribers and pharmacists, was the teaching effect. In our study, $77 \%$ of the prescribers and $69 \%$ of the pharmacists reported that they learned about interactions from the database. Glassman et al. [5] reported only minor improvement in the overall recognition of DDIs in a two time period investigation. There seem to be discrepancies between what physicians and pharmacists perceive and what they really experience in knowledge gain.

One of the most important limitations to the use of drug interaction warning systems is that they tend to overalert the prescribers. Even though we could not investigate the real frequency of overriding, the fact that only $20 \%$ of the prescribers and $25 \%$ of the pharmacist reported that the information was irrelevant sometimes or more often indicates that SFINX is perceived useful in the decision making 
process of drug-drug interactions. We have found no other studies investigating the user perception of web based drug-drug interaction warning systems. Since the usage of this kind of system is voluntary, the results from our study cannot be compared to results from studies on drug-drug interaction warning systems integrated into EHRs. In studies based on EHR integrated warning systems, the frequency of overriding of drug interaction alerts has been reported to vary between 32 and up to $96 \%$ [23-27]. In a study by Magnus et al. [29], as many as $76 \%$ of the prescribers' using a EHR integrated drug interaction warning system found the information provided through DDI alerts irrelevant to the patient at least sometimes or more often, and half of the respondents felt annoyed by the alerts. Answers depended on the various computer systems used and there was a strong agreement on the fact that severity grading of drug interaction information would be very useful ( 85 $\%)$.

The true frequency of overalerting cannot be estimated from the results from this study. It is more likely that overalerting is a minor problem for users of the web application than for users when SFINX is implemented in the EHR and gives automatic warnings. Further studies are needed to investigate the frequency of overalerting by SFINX.

We found female prescribers more likely to change their prescribing than men. This is in accordance with the result in a study by Sittig et al. [28], where women were more likely to accept safety alerts, feel empowered by the alerts and be relieved to receive an alert. The reason behind this difference is not known and more investigations would be needed to rule this out.

A possible limitation of the investigation was that the survey was sent to the registered users of SFINX, who have actively chosen to use the service, and therefore the results are likely to be more positive to the use of the interaction database than users who have SFINX integrated in EHR system. However, by addressing these users for the questionnaire we wanted the focus of the investigation to be on the content and usability of the interaction database, avoiding all possible issues of how the 
DDI database is integrated in the electronic health record system, or other problems which might occur through workflow and graphical user interface issues within the variety of EHR systems. Additionally, another limitation of this study was that those who did not respond may be more likely to dislike the database. In total, $74 \%$ of the prescribers reported that the information received made them change their prescribing sometimes or more often. This is in line with a study by Magnus et al. [29], where $70 \%$ of GPs reported changing their initial prescribing decision based on drug-drug interaction warnings at least sometimes or more often. In a study by Ko et al. [30], $49 \%$ of the prescribers reported to change their prescribing decision due to DDI warnings, with a lower percentage for physicians using computer generated alerts.

Additionally, further investigations are needed to track override rates of generated alerts in the integrated versions of SFINX in various electronic health record systems. Additional studies are needed to measure the real change of medication or dosage due to DDI alerts and to investigate possible improved patient outcome.

\section{Conclusion}

Based on the results from this study is is concluded that SFINX is often used in direct association with a patient consultation and information perceived results in change in patient handling. This may theoretically result in direct changes patient care and reduced occurrence of drug interactions.

\section{Authors contribution}

All authors have contributed to the design of the study, analysis of data and writing of manuscript.

\section{Statement on conflicts of interest}


M.L. Andersson and Y. Böttiger are, as employees of the Stockholm County Council and with no financial interest in the project, working with the quality and content of the SFINX database.

\section{Summary table}

What was already known on this topic:

- The web version of SFINX has more than 11000 registered users, mostly health care professionals

- Drug interaction warning systems may overalert the users

- Drug decision support systems can be difficult to use in clinical practise

What this study added to our knowledge

- SFINX is used when prescribers/pharmacist meet patients

- drug-drug interaction information causes changes in patient care

- receiving information from SFINX is educating

\section{References}

1. Tirkkonen T, Laine K. Drug interactions with the potential to prevent prodrug activation as a common source of irrational prescribing in hospital inpatients. Clin.Pharmacol.Ther. 2004 Dec;76(6):639-47. 
2. Andersson ML, Bottiger $Y$, Lindh JD, Wettermark B, Eiermann B. Impact of the drug-drug interaction database SFINX on prevalence of potentially serious drug-drug interactions in primary health care. Eur.J.Clin.Pharmacol. 2013 Mar;69(3):565-71.

3. Garg AX, Adhikari NK, McDonald H, Rosas-Arellano MP, Devereaux PJ, Beyene J, Sam J, Haynes RB. Effects of computerized clinical decision support systems on practitioner performance and patient outcomes: a systematic review. JAMA 2005 Mar 9;293(10):1223-38.

4. Coleman JJ, van der Sijs H, Haefeli WE, Slight SP, McDowell SE, Seidling HM, Eiermann B, Aarts J, Ammenwerth E, Ferner RE, et al. On the alert: future priorities for alerts in clinical decision support for computerized physician order entry identified from a European workshop. BMC.Med.Inform.Decis.Mak. 2013;13:111.

5. Glassman PA, Simon B, Belperio P, Lanto A. Improving recognition of drug interactions: benefits and barriers to using automated drug alerts. Med.Care 2002 Dec;40(12):1161-71.

6. Paterno MD, Maviglia SM, Gorman PN, Seger DL, Yoshida E, Seger AC, Bates DW, Gandhi TK. Tiering drug-drug interaction alerts by severity increases compliance rates. J.Am.Med.Inform.Assoc. 2009 Jan;16(1):40-6.

7. Bergk V, Gasse C, Schnell R, Haefeli WE. Requirements for a successful implementation of drug interaction information systems in general practice: results of a questionnaire survey in Germany. Eur.J.Clin.Pharmacol. 2004 Oct;60(8):595-602.

8. Bottiger Y, Laine K, Andersson ML, Korhonen T, Molin B, Ovesjo ML, Tirkkonen T, Rane A, Gustafsson LL, Eiermann B. SFINX-a drug-drug interaction database designed for clinical decision support systems. Eur.J.Clin.Pharmacol. 2009 Jun;65(6):627-33. 
9. Abarca J, Malone DC, Armstrong EP, Grizzle AJ, Hansten PD, Van Bergen RC, Lipton RB.

Concordance of severity ratings provided in four drug interaction compendia.

J.Am.Pharm.Assoc.(2003.) 2004 Mar;44(2):136-41.

10. Vitry Al. Comparative assessment of four drug interaction compendia. Br.J.Clin.Pharmacol. 2007 Jun;63(6):709-14.

11. Smithburger PL, Buckley MS, Bejian S, Burenheide K, Kane-Gill SL. A critical evaluation of clinical decision support for the detection of drug-drug interactions. Expert.Opin.Drug Saf 2011 Nov;10(6):871-82

12. Teich JM, Osheroff JA, Pifer EA, Sittig DF, Jenders RA. Clinical decision support in electronic prescribing: recommendations and an action plan: report of the joint clinical decision support workgroup. J.Am.Med.Inform.Assoc. 2005 Jul;12(4):365-76.

13. Sjoborg B, Backstrom T, Arvidsson LB, Andersen-Karlsson E, Blomberg LB, Eiermann B, Eliasson M, Henriksson K, Jacobsson L, Jacobsson U, et al. Design and implementation of a point-of-care computerized system for drug therapy in Stockholm metropolitan health region--Bridging the gap between knowledge and practice. Int.J.Med.Inform. 2007 Jul;76(7):497-506.

14. Sjoqvist F. A new classification system for drug interactions. Eur.J.Clin.Pharmacol. 1997;52(Suppl):327a.

15. Easyresearch 2014 [cited 2014 Jan 30] Available from www.easyresearch.se.

16. Lemon JS. The effect of reminders intervals on response rates for web surveys. In: Trotman M, editor. Survey and statistical computing IV. The impact of technology on the survey process. 2007. 
17. R Core Team. R: A language and environment for statistical computing. 2012 Available from http://www.R-project.org/.

18. Hayward J, Thomson F, Milne H, Buckingham S, Sheikh A, Fernando B, Cresswell K, Williams R, Pinnock H. 'Too much, too late': mixed methods multi-channel video recording study of computerized decision support systems and GP prescribing. J.Am.Med.Inform.Assoc. 2013 Jun;20(e1):e76-e84.

19. Ko Y, Malone DC, Skrepnek GH, Armstrong EP, Murphy JE, Abarca J, Rehfeld RA, Reel SJ, Woosley RL. Prescribers' knowledge of and sources of information for potential drug-drug interactions: a postal survey of US prescribers. Drug Saf 2008;31(6):525-36.

20. Yu KH, Sweidan $M$, Williamson $M$, Fraser $A$. Drug interaction alerts in software--what do general practitioners and pharmacists want? Med.J.Aust. 2011 Dec 19;195(11-12):676-80.

21.

22. 21. Ahearn MD, Kerr SJ. General practitioners' perceptions of the pharmaceutical decisionsupport tools in their prescribing software. Med.J.Aust. 2003 Jul 7;179(1):34-7.

22. Kortteisto T, Komulainen J, Makela M, Kunnamo I, Kaila M. Clinical decision support must be useful, functional is not enough: a qualitative study of computer-based clinical decision support in primary care. BMC. Health Serv.Res. 2012;12:349.

23. Buurma H, Schalekamp T, Egberts AC, De Smet PA. Compliance with national guidelines for the management of drug-drug interactions in Dutch community pharmacies. Ann.Pharmacother. 2007 Dec;41(12):2024-31. 
24. Jani YH, Barber N, Wong IC. Characteristics of clinical decision support alert overrides in an electronic prescribing system at a tertiary care paediatric hospital. Int.J.Pharm.Pract. 2011 Oct;19(5):363-6.

25. Slight SP, Nanji KC, Seger DL, Cho I, Volk LA, Bates DW. Overrides of clinical decision support alerts in primary care clinics. Stud.Health Technol.Inform. 2013;192:923.

26. van der Sijs $\mathrm{H}$, Aarts J, Vulto A, Berg M. Overriding of drug safety alerts in computerized physician order entry. J.Am.Med.Inform.Assoc. 2006 Mar;13(2):138-47.

27. Weingart SN, Toth M, Sands DZ, Aronson MD, Davis RB, Phillips RS. Physicians' decisions to override computerized drug alerts in primary care. Arch.Intern.Med. 2003 Nov 24;163(21):2625-31.

28. Sittig DF, Krall MA, Dykstra RH, Russell A, Chin HL. A survey of factors affecting clinician acceptance of clinical decision support. BMC.Med.Inform.Decis.Mak. 2006;6:6.

29. Magnus D, Rodgers S, Avery AJ. GPs' views on computerized drug interaction alerts: questionnaire survey. J.Clin.Pharm.Ther. 2002 Oct;27(5):377-82.

30. Ko Y, Abarca J, Malone DC, Dare DC, Geraets D, Houranieh A, Jones WN, Nichol WP, Schepers GP, Wilhardt M. Practitioners' views on computerized drug-drug interaction alerts in the VA system. J.Am.Med.Inform.Assoc. 2007 Jan;14(1):56-64. 